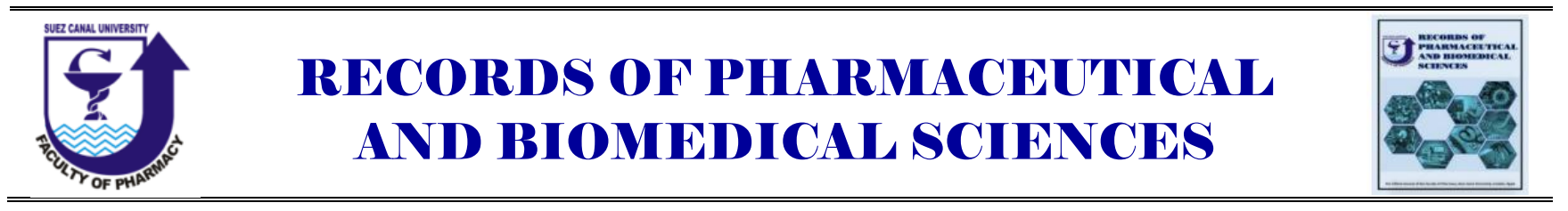

\title{
Identification methods of Candida isolated from vaginal infections
}

\author{
Aya Ali *, Marwa Azab, Ali Abdelrahman \\ Microbiology and Immunology Department, Faculty of Pharmacy, Suez Canal University, Egypt.
}

Received on: 22. 02. 2019

Revised on: 02. 03. 2019

Accepted on: 05. 03. 2019

Correspondence Author:

Tel:+2 01552137517

E-mail address:

ayamousa1988@gmail.com

\begin{abstract}
A number of methods of sampling the vagina for the presence of candida have been developed. Such techniques play an important role in the diagnosis and management of vaginal candidiasis. In the past, identification of candida isolated from the vagina has usually been limited to the genus Candida or to the species $C$. albicans. However, with the recognition that Candida species differ in the production of putative virulence factors and sensitivity to antifungal agents, greater emphasis has been placed on identification of isolates to species level. As a result, a range of commercially available systems for yeast identification can now be used in conjunction with traditional identification procedures. In this work, Candida detected by many phenotypic identification methods such as sabaroud dextrose agar medium, microscopical identification, sugar fermentation test and germ tube test. Polymerase chain reaction (PCR) also used as a fast and sensitive genotypic technic to identify Candida sp.
\end{abstract}

Keywords: Candida; isolation; identification; methodology, multiplex PCR

\section{Introduction}

Candida is as an opportunistic pathogen, presenting at the oral cavity, the gastrointestinal tract, the vaginal and the urinary environments (Pfaller and Diekema 2007). C. albicans commonly causes infections such as denture stomatitis, thrush, and urinary tract-infections, but also can make more severe systemic infections. These are frequently life-threatening, in immunocompromised individuals, whose numbers are constantly increasing due to organ transplant, chemotherapy, or, more importantly, to the prevalence of AIDS and Hepatitis C (Pfaller and Diekema 2007). Indeed, many microbiological laboratories providing a mycology service limit the level of yeast identification to Candida species only and the demonstration of antifungal susceptibility (Odds and Bernaerts, 1994). However, it is now becoming recognised that isolates of Candida species differ widely, both in their ability to cause infection (Cázares-Núñez et al., 2017; Odds and Bernaerts, 1994) and alsoin their susceptibility to antifungal agents (McCullough et al., 2004). Furthermore, the emergence of drug-resistant strains of candida in potentially fatal systemic forms of candidosis has highlighted the need for reliable methods of candida isolation and identification. This review provides an overview for the techniques currently available for identification of isolates. 


\section{Materials and Methods}

\subsection{Patients Analyzed and Sampling:}

One hundred and fifty-seven (157) vaginal swabs were obtained from women aged from (15 to 45 years old) which clinically diagnosed of genitourinary tract infections attending to AL-Sabaa Banat health care unit and obstetrics and gynecology private clinic. The lower vagina (vaginal introitus) was swabbed. One vaginal swab was collected from each patient with an informed consent.

The vaginal Swabs were placed into Sabouraud Dextrose Broth (SDB) (Difico, USA) transporting media. The transporting media maintained Candida viability for up to 4 days at room temperature or under refrigeration (Bhavan et al., 2010).

SDB (Difico, USA) Transporting media was prepared according to manufacturer's instruction: 30 grams were suspended in $1000 \mathrm{ml}$ of cold distilled water heated to dissolve, sterilized by autoclaving then distributed into $15 \mathrm{ml}$ capped plastic tubes and stored in a cool place. Sterile cotton-tipped swabs were used to collect the specimen. Each vaginal swab then was pushed down the medium depth. Swabs were kept cool, in an insulated box containing sufficient ice packs, during the transport period (Bhavan et al., 2010).

\subsection{Identification methods:}

\subsubsection{Morphological Identification}

On SDA colonies of Candida albicans are white to cream coloured, smooth, glabrous and yeast-like in appearance (Ogba et al., 2013).

\subsubsection{Microscopically Identification}

Smears were prepared from suspected colonies, put on slides cleaned with alcohol. They then heatfixed staining was done by flooding the smears with crystal violet solution for $1 \mathrm{~min}$ and then with Gram's iodine for $1 \mathrm{~min}$. After washing, the smears were decolorized with $95 \%$ ethanol and counter strained with aqueous basic fuchsine. The slide was subjected to observation of Candida morphology under oil immersion objective lens $(100 \mathrm{x})$ of a Bright Field microscope. Microscopic morphology shows spherical to sub spherical budding yeast-like cells or blast conidia, 2.0-7.0 x 3.0-8.5 $\mu \mathrm{m}$ in size (Bhavan et al. 2010; Ogba et al., 2013).

\subsubsection{Sugar fermentation test}

Fermentative yeasts recovered from clinical specimens produce carbon dioxide and alcohol. Production of gas rather than a $\mathrm{pH}$ shift is indicative of fermentation. Glucose, maltose, sucrose, lactose, galactose and trehalose were used in the test. The $5 \mathrm{ml}$ of carbohydrate $(\mathrm{pH}, 7.4)$ containing $1 \%$ peptone, $1 \%$ sugar, $0.3 \%$ beef extract and $0.5 \% \mathrm{NaCl}, 0.2 \%$ Bromothymol blue in distilled water medium was dispensed in sterilized Durham tube and $0.2 \mathrm{ml}$ of saline suspension of the test organism was added and incubated at $37^{\circ} \mathrm{C}$ for 10 days (Bhavan et al., 2010).

\subsubsection{Germ tube test (GTT)}

The germ tube test provides a simple, reliable and economical procedure for identification of Candida albicans which produce germ tube when incubated in serum at $35^{\circ} \mathrm{C}$ for 2.5 to 3 hours. A germ tube represents the initiation of hypha directly from the yeast cell. By sterile loop take a colony from isolated sample and inoculate it in an eppendorf tube containing human serum. After putting all samples in these tubes incubate the eppendorf tubes at $35^{\circ} \mathrm{C}$ for 3 hours. After incubation we can examination the samples under the light microscope. Positive samples which give a hypha indicate to Candida albicans found (Akortha, Nwaugo, and Chikwe, 2009).

\subsubsection{Identification by Multiplex PCR}

Multiplex PCR reaction was performed on the direct sample by using 7 primers and PCR condition as shown in (table 1). PCR reaction was performed in a $50 \mu \mathrm{l}$ volume containing $20 \mu \mathrm{l}$ vaginal swab broth solution, 5X PCR buffer (Thermo, USA), $2.5 \mathrm{mM} \mathrm{MgCl}_{2}$ (Thermo, USA), $630 \mu \mathrm{M}$ PCR nucleotide Mix - $10 \mathrm{mM}$ each (Thermo, USA), $2 \mu$ lfrom each 7 primers, $1 \mu 1$ Go Tag DNA Polymerase (Fermentase, USA). The volume for each PCR reaction was completed to $50 \mu \mathrm{l}$ with nuclease free water (Thermo, USA) (Liguori et al. 2007). PCR products were analysed by electrophoresis through a 2\%agarose gel (Bioshop, Canada) containing ethidium bromide (Sigma,USA), and UV visualization were performed according to the protocols provided(G: box, SYNGENE, Cambridge, England).The length of the bands was measured by UV Light software according to (table 2) and reference Candida albicans strain (ATCC 90028) used to compare the result with it (Liguori et al.,2007) 
Table (1): Primer sequences and PCR conditions for Multiplex PCR.

\begin{tabular}{lll}
\hline \multicolumn{1}{c}{ Target gene } & \multicolumn{1}{c}{ PCR Primer Sequences 5”- 3” } & \multicolumn{1}{c}{ PCR Conditions } \\
\hline ITS1F gene & (5-CCAGCG CTT AAT TGC G-3) & initial denaturation, $92^{\circ} \mathrm{C} 2 \mathrm{~min}$; \\
ITS1K gene & (5-ATC GTC TGA ACA AGGCCT GC-3) & 35 cycles of denaturation $\left(95^{\circ} \mathrm{C}, 1\right.$ \\
ITS2D gene & (5-GAG AAC CAA GAG ATC CGT TGTTG-3) & min), annealing $\left(50^{\circ} \mathrm{C}, 1 \mathrm{~min}\right)$, \\
ITS1 gene & (5-TCC GTA GGT GAA CCTGCG G-3) & and extension $\left(72^{\circ} \mathrm{C}, 1 \mathrm{~min}\right)$; and \\
ITS2 gene & (5-GCT GCG TTC TTC ATC GAT CG-3) & final extension, $72^{\circ} \mathrm{C}, 10 \mathrm{~min}$ \\
CA3 gene & (5-GGT TTG GAAAGA CGG TAG-3) & (Liguori et al. 2007). \\
CA4 gene & (5-AGT TTG AAG ATA TAC GTGGTA G-3) &
\end{tabular}

\section{Results}

\subsection{Demographic data}

The present study was conducted with a total of 157 women clinically diagnosed of genitourinary tract infections and by using the conventional culture technique only 100 isolates were identified as Candida with a prevalence rate (64\%).

\subsection{Identification Tests}

\subsubsection{Morphological Identification on SDA}

One hundred isolates showed white to cream coloured colonies, smooth and glabrous in appearance (Figure 1).

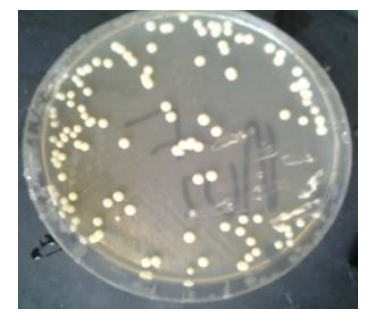

Figure (1): White colonies Candida spp on SDA.

\subsubsection{Microscopically Identification}

One hundred isolates show round to oval budding yeast-like cells under microscope (Figure 2).

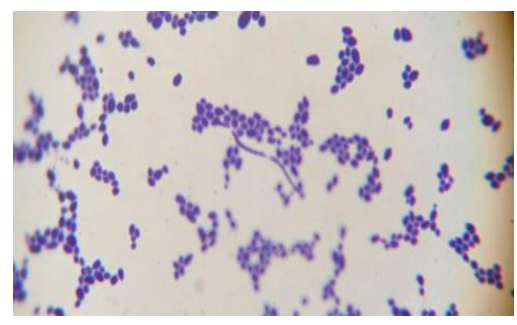

Figure (2): Candida spp under microscope

\subsubsection{Sugar fermentation test}

By these test 91 samples identified as Candida albicans and 9 samples identified as Candida glabrata (table 3 and figure $\mathbf{3}$ ).

Table (3): Sugar fermentation tests for Candida sp

\begin{tabular}{|l|l|l|}
\hline sugar & C. albicans & C. glabrata \\
\hline Glucose & +ve & +ve \\
\hline Maltose & +ve & -ve \\
\hline Sucrose & -ve & -ve \\
\hline Lactose & -ve & -ve \\
\hline Galactose & +ve & -ve \\
\hline Trehalose & +ve & +ve \\
\hline
\end{tabular}

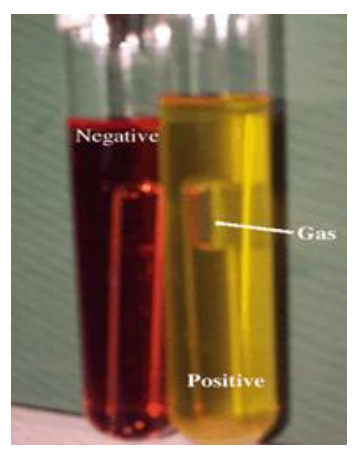

Figure (3): Sugar fermentation tests for Candida spp

\subsubsection{Germ tube test (GTT)}

This test especially for identification Candida albicans from other types of Candida spp. 93 samples (93\%) showed germ tube under microscope (Figure 4). 
Table (2): lists of the primers and the generated PCR products.

\begin{tabular}{|l|l|l|l|l|l|l|l|l|}
\hline Organism & ITS1 & ITS1F & ITS1K & ITS2 & ITS2D & CA3 & CA4 & PCR product (bp) \\
\hline C glabrata & + & - & - & + & + & - & - & $482-483 / 462-463$ \\
\hline C guilliermondii & + & - & - & + & + & - & - & $248 / 228$ \\
\hline C famata & - & + & - & + & + & - & - & $234 / 214$ \\
\hline C kefux & - & - & + & + & + & - & - & $249 / 229$ \\
\hline C parapsilesis & + & - & - & + & + & - & - & $229 / 209$ \\
\hline C tropicalis & + & - & - & + & + & - & - & $218 / 199$ \\
\hline C albicans & + & - & - & + & + & + & + & $218-219 / 198-$ \\
\hline C kxussil & + & - & - & + & + & - & - & $199 / 110$ \\
\hline C lusitaniae & + & - & - & + & + & - & - & $148 / 166$ \\
\hline C dubliniensis & + & - & - & - & + & - & - & 198 \\
\hline
\end{tabular}

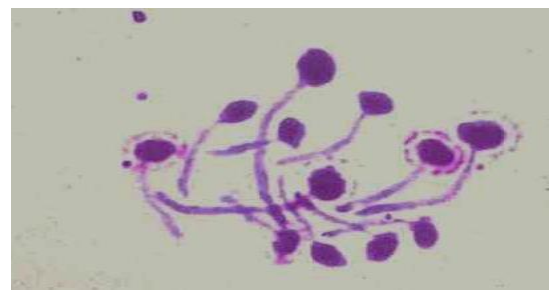

Figure (4): Germ tube under microscope

\subsubsection{Identification by multiplex PCR}

Ninety-eight (98) isolates (98\%) identified as Candida albicans which give the same bands of Candida albicans reference strain (ATCC 90028) at (218-219bp), (198_199bp), (110bp) while 2isolates (2\%) found Candida glabrata show bands at (482483bp), (462-463bp) (Figure 5).

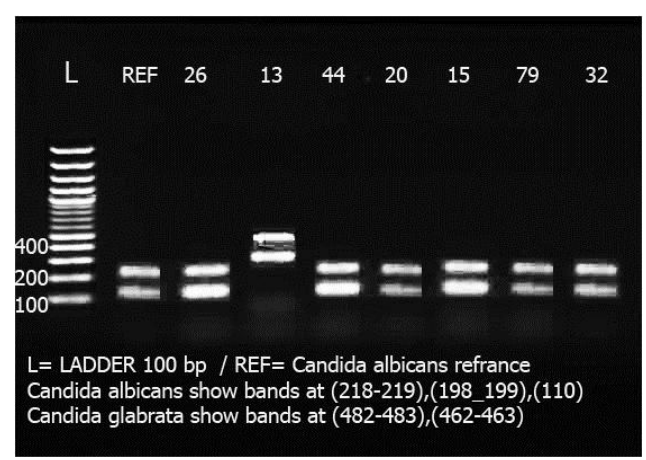

Figure (5): Identification by muliplex PCR

\section{Discussion}

The observation in this study that $C$. albicans had the high incidence rate $(63.69 \%)$ among the yeast isolates studied is in agreement with the reports of other workers (Richter et al. 2005; Sobel et al. 1998; Tatfeng et al. 2004). (Richter et al. 2005)reported a 76\% incidence rate among his yeast isolates. (Sobel et al. 1998) reported an 80$90 \%$ incidence rate. (Tatfeng et al. 2004) reported C. albicans to be the most convicted yeast isolate in urinary tract infections.

Culture of Candida from vaginal isolates is the most popular method for identification and it depend on initial growth on primary selective agar plates. This is followed by additional tests for complete identification of the isolates. This required a period of 48 to $72 \mathrm{~h}$ before confirmation of Candida can be made (Bhavan et al. 2010).

The phenotypic methods for the identification of Candida spp., although simple and inexpensive, impose some limitations. These methods are timeconsuming and/or more often unable to differentiate $C$. albicans from other types of Candida. The germ-tube production test has the advantage to be simple and effective in the economical and fast identification of $C$. albicans (Fisher and Cook 1998; Lacaz 2002). Many authors estimated sensitivity and specificity of the germtube test, finding results between 93 and $98.8 \%$, and between 73.3 and $100 \%$, respectively (Campbell et al. 1998; Conceição et al. 2005; Gatica et al. 2002).This study showed 93 isolates give germ tube under microscope. This result must be comparing with the results given by other sensitive and specific identification methods like multiplex PCR which showed 98 isolates identified as Candida albicans. 
To improve the quality of our diagnostic research, we have set up a multiplex PCR assay for the identification of major species of candida found in vaginal candidiasis to prevent any mistake in treatment and time consuming. The PCR assay on vaginal swab broth solutions obtained directly from the samples without DNA extraction. The advantages of this method are as follows: it does not require use of expensive or toxic chemical substances such as proteinase $\mathrm{K}$ or phenolchloroform, high sample volume throughput (Sullivan et al. 1996), the total time from species identification is $5 \mathrm{~h}$, compared to a mean of 5 days by routine phenotypic culture, high sensitivity and specificity, ability to detect low levels of yeasts from minimal sample volumes (Wahyuningsih et al. 2000), identification of more than one species of yeast is possible in mixed cultures, with no crossreaction or interference with bacteria and viruses likely to be present in vaginal rinse solutions, ease to perform and it is available to most laboratories (Mannarelli and Kurtzman 1998), and no modifications or changes in routine practice were necessary for the clinicians or the laboratory technicians, who were able to use the same samples used for conventional morphological and metabolic examination for the PCR assay. Finally, considering the continuous decrease of the cost of purchasing a thermal cycler and the reagents necessary to use it, the estimated cost for this assay is like that of routine phenotypic culture identification.

In this study, we accomplish that the traditional method for detection of candida species as germ tube test or manual biochemical reactions may resulted in error results, in the other hand the new method for identification like multiplex PCR are best method for confirmation this identification. Molecular methods can give absolute identification with one-day results and do not need previous cultures. Thus, the diagnostic can be made directly from the material collected from patients, giving valuable information for patient organization.

\section{Conclusion}

The Candida colonization rate was found to be 64 $\%$ in Ismailia. Germ tube test was specific test for Candida albicans and can differ it from other species of Candida. Multiplex PCR was easy and most sensitive method for identification the different species of Candida.

\section{Acknowledgments}

The authors will like to thank the members of of Pharmaceutical Sciences Department, Faculty of Pharmacy, Suez Canal University, Ismailia, Egypt.

\section{Conflict of interest}

The authors declare that there is no conflict of interest.

\section{References}

Akortha, E. E., V. O. Nwaugo, and N. O. Chikwe. 2009. "Antifungal Resistance among Candida Species from Patients with Genitourinary Tract Infection Isolated in Benin City, Edo State, Nigeria." African Journal of Microbiology Research 3(11):694-99.

Bhavan, P. Saravana, R. Rajkumar, S. Radhakrishnan, C. Seenivasan, and S. Kannan. 2010. "Culture and Identification of Candida Albicans from Vaginal Ulcer and Separation of Enolase on SDS-PAGE." International Journal of Biology 2(1):84.

Campbell, C. K., A. D. Holmes, K. G. Davey, A. Szekely, and D. W. Warnock. 1998. "Comparison of a New Chromogenic Agar with the Germ Tube Method for Presumptive Identification Of Candida Albicans." European Journal of Clinical Microbiology \& Infectious Diseases 17(5):367-68.

Cázares-Núñez, Claudia, J. Araiza, I. Arellano, and A. Bonifaz. 2017. "Alerta Epidemiológica: Infección Por Candida Auris." Dermatologia Revista Mexicana 61(6):533-36.

Conceição, G. C., Petrônio Primo Coêlho, M. A. de Sousa Júnior, Milena L. Pereira, DSCG Miguel, and Maria Betânia P. Toralles. 2005. "Avaliação Do Tubo Germinativo Em Secreção Vaginal a Fresco Para Triagem de Candida Albicans: Um Teste Rápido." Rev NewsLab 73:106-12.

Fisher, Frances W. and Norma B. Cook. 1998. Fundamentals of Diagnostic Mycology. WB Saunders Company.

Gatica, M., José Luis, B. Goic, T. Martínez, María Angélica, S. de O. Reid, P. Céspedes, E. Arias, María Cecilia, and S. Ovalle. 2002. "Utilidad Del Agar Cromocandida Para El Diagnostico Diferencial de Candida Spp Aisladas de Muestras Vaginales." Revista Chilena de Obstetricia y Ginecología 67(4):300-304.

Lacaz, C. S. 2002. "Tratado de Micologia Lacaz CS, Porto E, Martins JEC, Heins-Vaccari EM, Melo NT." Tratado de Micologia Médica-Lacaz. 
Editora Sarvier, São Paulo.

Liguori, Giorgio, Angela Lucariello, Giuseppe Colella, Antonio De Luca, and Paolo Marinelli. 2007. "Rapid Identification of Candida Species in Oral Rinse Solutions by PCR." Journal of Clinical Pathology 60(9):1035-39.

Mannarelli, B. M. and C. P. Kurtzman. 1998. "Rapid Identification of Candida Albicansand Other Human Pathogenic Yeasts by Using Short Oligonucleotides in a PCR." Journal of Clinical Microbiology 36(6):1634-41.

McCullough, Michael J., Jacks J. Jorge, Flavio Lejbkowicz, Eli Lefler, Faris Nassar, Karl V Clemons, and David A. Stevens. 2004. "Genotypic Differences of Candida Albicans and C. Dubliniensis Isolates Related to Ethnic/Racial Differences within the Same Geographic Area." Mycopathologia 158(1):39-41.

Odds, Frank C. and R. I. A. Bernaerts. 1994. "CHROMagar Candida, a New Differential Isolation Medium for Presumptive Identification of Clinically Important Candida Species." Journal of Clinical Microbiology 32(8):1923-29.

Ogba, Ofonime Mark, Lydia Nyong Abia-Bassey, James Epoke, Baki Idasa Mandor, and Godwin Dickson Iwatt. 2013. "Characterization of Candida Species Isolated from Cases of Lower Respiratory Tract Infection among HIV/AIDS Patients in Calabar, Nigeria." World Journal of AIDS 3(03):201.

Liguori, Giorgio, Angela Lucariello, Giuseppe Colella, Antonio De Luca, and Paolo Marinelli.
2007. "Rapid Identification of Candida Species in Oral Rinse Solutions by PCR." Journal of Clinical Pathology 60(9):1035-39.

Mannarelli, B. M. and C. P. Kurtzman. 1998. "Rapid Identification of Candida Albicansand Other Human Pathogenic Yeasts by Using Short Oligonucleotides in a PCR." Journal of Clinical Microbiology 36(6):1634-41.

McCullough, Michael J., Jacks J. Jorge, Flavio Lejbkowicz, Eli Lefler, Faris Nassar, Karl V Clemons, and David A. Stevens. 2004. "Genotypic Differences of Candida Albicans and C. Dubliniensis Isolates Related to Ethnic/Racial Differences within the Same Geographic Area." Mycopathologia 158(1):39-41.

Odds, Frank C. and R. I. A. Bernaerts. 1994. "CHROMagar Candida, a New Differential Isolation Medium for Presumptive Identification of Clinically Important Candida Species." Journal of Clinical Microbiology 32(8):1923-29.

Ogba, Ofonime Mark, Lydia Nyong Abia-Bassey, James Epoke, Baki Idasa Mandor, and Godwin Dickson Iwatt. 2013. "Characterization of Candida Species Isolated from Cases of Lower Respiratory Tract Infection among HIV/AIDS Patients in Calabar, Nigeria." World Journal of AIDS 3(03):201.

Wahyuningsih, Retno, Hans-Joachim Freisleben, Hans-Günther Sonntag, and Paul Schnitzler. 2000. "Simple and Rapid Detection of Candida Albicans DNA in Serum by PCR for Diagnosis of Invasive Candidiasis." Journal of Clinical Microbiology 38(8):3016-21. 